Article

\title{
Impact of the Graphite Fillers on the Thermal Processing of Graphite/Poly(lactic acid) Composites
}

\author{
Daniel Kaczor $^{1,2, *}$, Kacper Fiedurek ${ }^{1,2}{ }^{,}$Krzysztof Bajer $^{2}$, Aneta Raszkowska-Kaczor ${ }^{2}$, Grzegorz Domek ${ }^{1}{ }^{1}$, \\ Marek Macko ${ }^{1}{ }^{(}$, Piotr Madajski ${ }^{3}\left[\right.$ and Pawel Szroeder ${ }^{4}$ \\ 1 Faculty of Mechatronics, Kazimierz Wielki University, Kopernika 1, 85-074 Bydgoszcz, Poland; \\ kacper.fiedurek@impib.lukasiewicz.gov.pl (K.F.); gdomek@ukw.edu.pl (G.D.); mackomar@ukw.edu.pl (M.M.) \\ 2 Łukasiewicz Research Network-Institute for Engineering of Polymer Materials and Dyes, Marii \\ Skłodowskiej-Curie 55, 87-100 Toruń, Poland; krzysztof.bajer@impib.lukasiewicz.gov.pl (K.B.); \\ aneta.kaczor@impib.lukasiewicz.gov.pl (A.R.-K.) \\ 3 Faculty of Chemistry, Nicolaus Copernicus University, Gagarina 7, 87-100 Toruń, Poland; \\ piotr.madajski@doktorant.umk.pl \\ 4 Institute of Physics, Kazimierz Wielki University, Powstańców Wielkopolskich 2, 85-090 Bydgoszcz, Poland; \\ psz@ukw.edu.pl \\ * Correspondence: daniel.kaczor@impib.lukasiewicz.gov.pl
}

check for updates

Citation: Kaczor, D.; Fiedurek, K.; Bajer, K.; Raszkowska-Kaczor, A.; Domek, G.; Macko, M.; Madajski, P.; Szroeder, P. Impact of the Graphite Fillers on the Thermal Processing of Graphite/Poly(lactic acid) Composites. Materials 2021, 14, 5346. https://doi.org/10.3390/ma14185346

Academic Editors: Georgios Bokias and Loic Hilliou

Received: 30 June 2021

Accepted: 11 September 2021

Published: 16 September 2021

Publisher's Note: MDPI stays neutral with regard to jurisdictional claims in published maps and institutional affiliations.

Copyright: (c) 2021 by the authors. Licensee MDPI, Basel, Switzerland. This article is an open access article distributed under the terms and conditions of the Creative Commons Attribution (CC BY) license (https:// creativecommons.org/licenses/by/ $4.0 /)$.

\begin{abstract}
To assess the impact of graphite fillers on the thermal processing of graphite/poly(lactic acid) (PLA) composites, a series of the composite samples with different graphite of industrial grade as fillers was prepared by melt mixing. The average size of the graphite grains ranged between $100 \mu \mathrm{m}$ and $6 \mu \mathrm{m}$. For comparative purposes, one of the carbon fillers was expandable graphite. Composites were examined by SEM, FTIR, and Raman spectroscopy. As revealed by thermogravimetric (TG) analyses, graphite filler slightly lowered the temperature of thermal decomposition of the PLA matrix. Differential scanning calorimetry (DSC) tests showed that the room temperature crystallinity of the polymer matrix is strongly affected by the graphite filler. The crystallinity of the composites determined from the second heating cycle reached values close to $50 \%$, while these values are close to zero for the neat polymer. The addition of graphite to PLA caused a slight reduction in the oxidation induction time (OIT). The melt flow rate (MFR) of the graphite/PLA composites was lower than the original PLA due to an increase in flow resistance associated with the high crystallinity of the polymer matrix. Expandable graphite did not cause changes in the structure of the polymer matrix during thermal treatment. The crystallinity of the composite with this filler did not increase after first heating and was close to the neat PLA MFR value, which was extremely high due to the low crystallinity of the PLA matrix and delamination of the filler at elevated temperature.
\end{abstract}

Keywords: poly(lactic acid); graphite; composites; room temperature crystallinity; oxidation induction time; melt flow rate

\section{Introduction}

Poly(lactic acid) produced from renewable resources has currently a principal position on the market of biodegradable polymers [1]. To tailor its properties to specific engineering applications, such as mechanical and automotive parts, electronic and electrical devices, or electrodes in electrochemical devices, it is necessary to tune its properties by combining the polymer matrix with different dispersed phases [2]. Carbon nanomaterials such as carbon nanotubes and graphene with its superior thermal and electrical properties can be used as a filler that improves some specific properties, such as stiffness, thermal stability, fire retardancy, and lower permeability [3]. The addition of graphene oxide to the polymer matrix results in the improvement of the Young modulus and an inhibition of the bacteria proliferation [4]. Due to the improved mechanical properties and electrical conductivity, graphene/PLA composites are considered as a filament for 3D printing [5] and an efficient electromagnetic interference shielding material $[6,7]$. 
Most pristine PLAs are in an amorphous state and tend to degrade during thermal processing, presenting a rapid reduction of molecular weight due to a polymer chain scission $[8,9]$. Graphene and graphite fillers do not only modify the properties of composites, but also affect the processability of the PLA matrix. The polymer crystallinity plays an important role in determining the physical properties that can be employed for specific applications of PLA during the processing, and it can be increased by nucleating agents. It has been shown that the crystallization behavior of PLA can be altered by the incorporation of the graphene oxides [10] and carbon nanotubes [11,12] into the PLA matrix. Use of the graphene oxide filler resulted in an increase of the degree of crystallinity to the level of $27 \%$ at cooling rate of $10^{\circ} \mathrm{C} / \mathrm{min}$ [10]. In turn, the crystallinity of the PLA matrix after the introduction of carbon nanotubes reaches the value of $20 \%$ [12]. As we show in this work, graphite fillers cause an increase in crystallinity above $40 \%$.

The crystallization process assisted by the carbon fillers is influenced by the thermal history of the composite. In order to fully exploit the application potential of composites, apart from case studies on the specific functionalities of these materials, studies of the influence of industrial-grade graphite fillers on the processability of graphene and graphite/PLA are required.

To meet these needs, we conducted extensive studies of neat PLA (as reference) and PLA composites with various graphite fillers of industrial grade using FTIR and Raman spectroscopy, TGA, DSC, OIT, and MFR. As fillers, we used graphite powders of various grain sizes ranging from 6 to $100 \mu \mathrm{m}$ and expandable graphite. The main focus of this work is the relationship between the graphite filler morphology and thermal phase transitions of the polymer matrix (glass transition, crystallization, and melting) that usually occur during the thermal processing. We show that industrial grade graphite powders can act as a nucleation agent and influence the polymer processing history by slowing down the degradation processes of the polymer matrix.

\section{Materials and Methods}

\subsection{Materials}

As a PLA matrix, the Ingeo ${ }^{\mathrm{TM}}$ Biopolymer $3260 \mathrm{HP}$ was selected, with density = $1.24 \mathrm{~g} / \mathrm{cm}^{3}$, mass-average molar mass $=107.5 \mathrm{Da}$, and polydispersity index $=1.68$, supplied by NatureWorks (Minnetonka, MN, USA).

The following graphite micropowders of industrial grade were used as fillers: MG192 (100 mesh, carbon content 92\%), MG394 (325 mesh, carbon content 94\%), MG1596 (1500 mesh, carbon content 96\%), and MG3096 (3000 mesh, carbon content 96\%). In addition to chemically unmodified powders, expandable graphite EG290 (+400 mesh, carbon content $80 \%$, expansion temperature $>200{ }^{\circ} \mathrm{C}$ ) intercalated with sulphur compounds was also used. All carbon powders were supplied by Sinograf SA (Toruń, Poland).

Apart from drying, all materials were used as received.

\subsection{Composite Preparation}

Prior to the compounding, unprocessed PLA granulate was dried at a temperature of $80^{\circ} \mathrm{C}$ for $8 \mathrm{~h}$. Before introducing graphite fillers, the neat PLA resin was premixed at $190^{\circ} \mathrm{C}$ for 2.5 min using a Plasti-Corder ${ }^{\circledR}$ Lab-Station (Brabender, South Hackensack, NJ, USA). Graphite powders were added with an approximate weight ratio of 1:3 for a mixing time of $2 \mathrm{~min}$, with a blade rate of $50 \mathrm{rpm}$, at $190^{\circ} \mathrm{C}$. The obtained blends were coded according to the type of graphite in the composite, as shown in Table 1. 
Table 1. Labeling, composition and processing method of the tested graphite/PLA composites.

\begin{tabular}{lccc}
\hline \multicolumn{1}{c}{ Code } & PLA (wt $\%)$ & Graphite (wt\%) & Sample Preparation Method \\
\hline PLA & PLA3260HP (100) & - & Unprocessed granulate \\
NG/PLA & PLA3260HP (100) & - & Melt mixing \\
EG290/PLA & PLA3260HP (73) & EG290 (27) & Melt mixing \\
MG192/PLA & PLA3260HP 74 & MG192 (26) & Melt mixing \\
MG394/PLA & PLA3260HP (75) & MG394 (25) & Melt mixing \\
MG1596/PLA & PLA3260HP (79) & MG1596 (21) & Melt mixing \\
MG3096/PLA & PLA3260HP (76) & MG3096 (24) & Melt mixing \\
\hline
\end{tabular}

\subsection{Material Characterization}

\subsubsection{Phase Morphology Analysis}

Scanning electron microscopy (SEM, SU8010, Hitachi, Japan) was used for studying the morphology of both the graphite fillers and graphite/PLA composites. For SEM imaging, graphite flakes and micropowders were deposited on conductive carbon adhesive tapes.

\subsubsection{Chemical Structure Analysis}

ATR-FTIR spectra were measured using the Agilent Technologies Cary 630 ATR-FTIR spectrometer (Agilent, Santa Clara, CA, USA), over the wavenumber range of $4000 \mathrm{~cm}^{-1}$ to $400 \mathrm{~cm}^{-1}$ with a resolution of $2 \mathrm{~cm}^{-1}$.

Raman spectra were recorded in backscattering geometry, with a Senterra Raman microscope (Bruker Optik, Billerica, MA, USA), using a $2 \mathrm{~mW}$ laser beam with a wavelength of $532 \mathrm{~nm}$ as an excitation light source. Both the ATR-FTIR and Raman spectra were acquired at ambient temperatures.

\subsubsection{Thermal Behavior and Stability Analysis}

Thermal gravimetric analyses (TGA) were carried out using an analyzer TG/DSC STA 449 F5 Jupiter (NETZSCH Instruments, Selb, Germany). Samples were measured in a crucible with a mass of about 4-6 mg. Composites were tested under nitrogen at temperatures ranging from $30^{\circ} \mathrm{C}$ to $1050{ }^{\circ} \mathrm{C}$ with a heating rate of $10^{\circ} \mathrm{C} / \mathrm{min}$.

Differential scanning calorimetry (DSC) was performed with a calorimeter DSC1 (Mettler-Toledo, Swiss) calibrated with pure indium and zinc standards under nitrogen atmosphere at gas flow rate $50 \mathrm{~cm}^{3} / \mathrm{min}$. Each sample of 5-7 $\mathrm{mg}$ was sealed in an aluminum crucible and heated from $0{ }^{\circ} \mathrm{C}$ to $300{ }^{\circ} \mathrm{C}$. After the first heating scan, the sample in the crucible was cooled to $0{ }^{\circ} \mathrm{C}$ and reheated to $300{ }^{\circ} \mathrm{C}$ (second heating scan). The heating/cooling rate was $10^{\circ} \mathrm{C} / \mathrm{min}$. Before the cooling and second heating scan, the sample was kept at a constant temperature of $300{ }^{\circ} \mathrm{C}$ and $0{ }^{\circ} \mathrm{C}$ for $3 \mathrm{~min}$, respectively. The inflection point of each glass transition was taken as a glass transition temperature, $T_{\mathrm{g}}$. Crystallization and melting peak position were taken as a crystallization $T_{\mathrm{c}}$ and melting temperatures $T_{\mathrm{m}}$, respectively. Crystallization and melting enthalpies were evaluated from the integrated areas of the peaks.

The room temperature crystallinity, $X_{c}$, of PLA composites was evaluated using the following expression:

$$
X_{c}=\left(\frac{\Delta H_{m}-\Delta H_{c c}}{w \Delta H_{m}^{0}}\right) \cdot 100 \%
$$

where $\Delta H_{m}$ is the enthalpy of melting $(\mathrm{J} / \mathrm{g}), \Delta H_{c c}$ is the cold crystallization enthalpy $(\mathrm{J} / \mathrm{g})$, $\Delta H_{m}^{0}$ is the melting enthalpy of $100 \%$ crystalline PLA $(93 \mathrm{~J} / \mathrm{g})$, and $w$ is the fraction of the polymer in the composite materials [13]. The experiment was performed in accordance with the ISO 11357-(1-3): 2009 standards.

The Mettler Toledo DSC1 calorimeter was also used to study thermal degradation of polymer matrix. OIT was measured at the isothermal temperature of $230{ }^{\circ} \mathrm{C}$ and gas flow rate of $50 \mathrm{~cm}^{3} / \mathrm{min}$. Each sample of 6-8 $\mathrm{mg}$ was heated under nitrogen from 50 to $230{ }^{\circ} \mathrm{C}$ at heating rate of $10^{\circ} \mathrm{C} / \mathrm{min}$. After reaching the required temperature, the sample was kept under nitrogen for 5 min to obtain thermodynamic equilibrium conditions. Then, the 
gas flow was changed from nitrogen to oxygen and, still under isothermal conditions, the onset of the exothermal signal (oxidation) was measured. The experiment was performed in accordance with the requirements of the ISO 11357-6:2018 standard.

The melt flow rate (MFR) of the composites was determined according to the PN-EN ISO 1133:2011 standard with a Dynisco LMI 4003 capillary plastometer. The measurements were carried out under the piston loading of $2.16 \mathrm{~kg}$ at $190^{\circ} \mathrm{C}$.

\section{Results}

\subsection{Phase Morphology Analysis}

Figure 1 shows SEM images of graphite fillers and graphite/PLA composites after melt mixing at $190{ }^{\circ} \mathrm{C}$. In sample EG290, the size of the graphite flakes was found to be $400 \pm 100 \mu \mathrm{m}$, while the thickness was about $20 \mu \mathrm{m}$. The mean sizes of flakes in MG192 was estimated to be $107 \pm 55 \mu \mathrm{m}$ and thickness was found to be about $10 \mu \mathrm{m}$. The average size of the MG394, MG1596, and MG3096 micropowders are $14 \pm 5 \mu \mathrm{m}, 10 \pm 4 \mu \mathrm{m}$, and $6 \pm 2 \mu \mathrm{m}$, respectively.
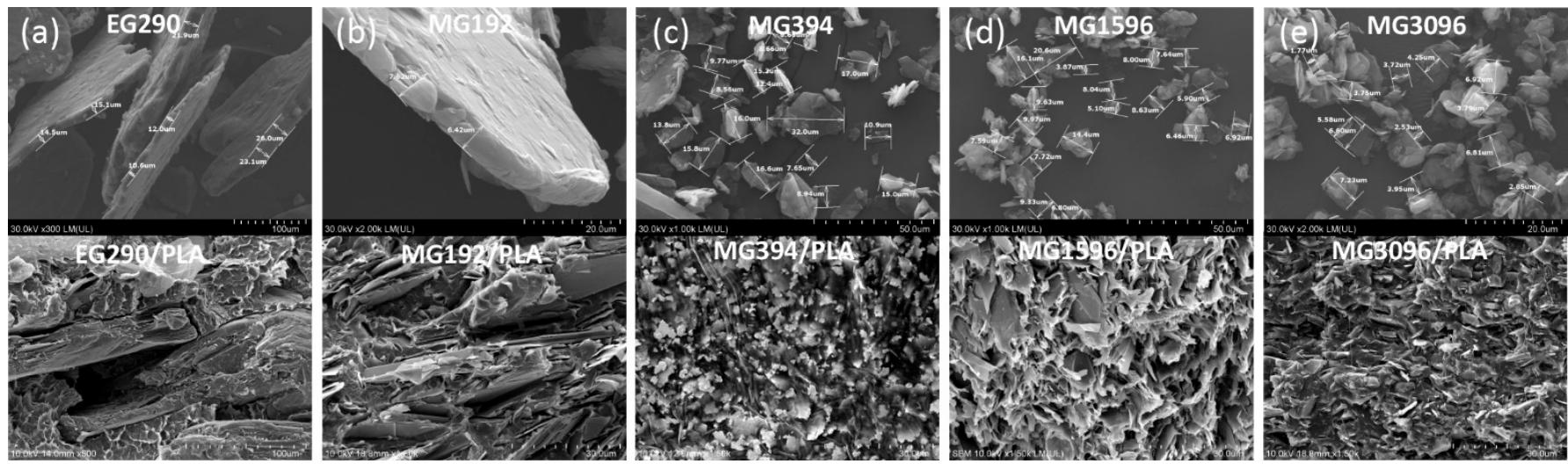

Figure 1. SEM images of neat graphite fillers (top) and graphite/PLA composites after mixing at $190{ }^{\circ} \mathrm{C}$ (bottom): (a) EG290/PLA, (b) MG192/PLA, (c) MG394/PLA, (d) MG1596/PLA and (e) MG3096/PLA.

The morphology of the EG290/PLA composite (Figure 1a) differs significantly from other composites. We can see that the expandable graphite flakes EG290 delaminated during mixing. The structure of composites with graphite micropowders MG192, MG396, MG1596, and MG3096 is more homogeneous with the increasingly smaller size of the graphite grains (Figure $1 \mathrm{~b}-\mathrm{e}$ ).

\subsection{FTIR and Raman Analyses}

Figure 2 shows ATR-FTIR and Raman spectra of the composites. The upper spectra were obtained for the raw PLA and PLA subjected to the melting process at $190^{\circ} \mathrm{C}$ (NG/PLA). The remaining spectra were obtained for samples of composites with graphite filler.

The infrared absorption spectra graphite/PLA composites contain the bands that are assigned to the PLA-based polymer [14,15]. Two bands at 755 and $868 \mathrm{~cm}^{-1}$ are attributed to the crystalline and amorphous phases of the polymer. The stretching modes of the $\mathrm{C}-\mathrm{CH}_{3}$ group appear at $1041 \mathrm{~cm}^{-1}$ while the symmetric and asymmetric stretching modes of the C-O-C group appear at 1079 (symm.), 1180, and $1266 \mathrm{~cm}^{-1}$ (asymm.), respectively. The band at $1127 \mathrm{~cm}^{-1}$ is assigned to the rocking modes of the $\mathrm{CH}_{3}$ group. Characteristics of the $\mathrm{CH}$ and $\mathrm{CH}_{3}$ symmetric bending modes appear at 1360 and $1382 \mathrm{~cm}^{-1}$ while the band corresponding to the asymmetric bending modes is found at $1454 \mathrm{~cm}^{-1}$. Then, the $\mathrm{C}=\mathrm{O}$ stretching modes of the ester group appear at $1746 \mathrm{~cm}^{-1}$. There are also weak bands at 2946 and $2994 \mathrm{~cm}^{-1}$ attributed to the asymmetric stretching modes of the $\mathrm{CH}_{3}$ group (not shown in Figure 2a). 

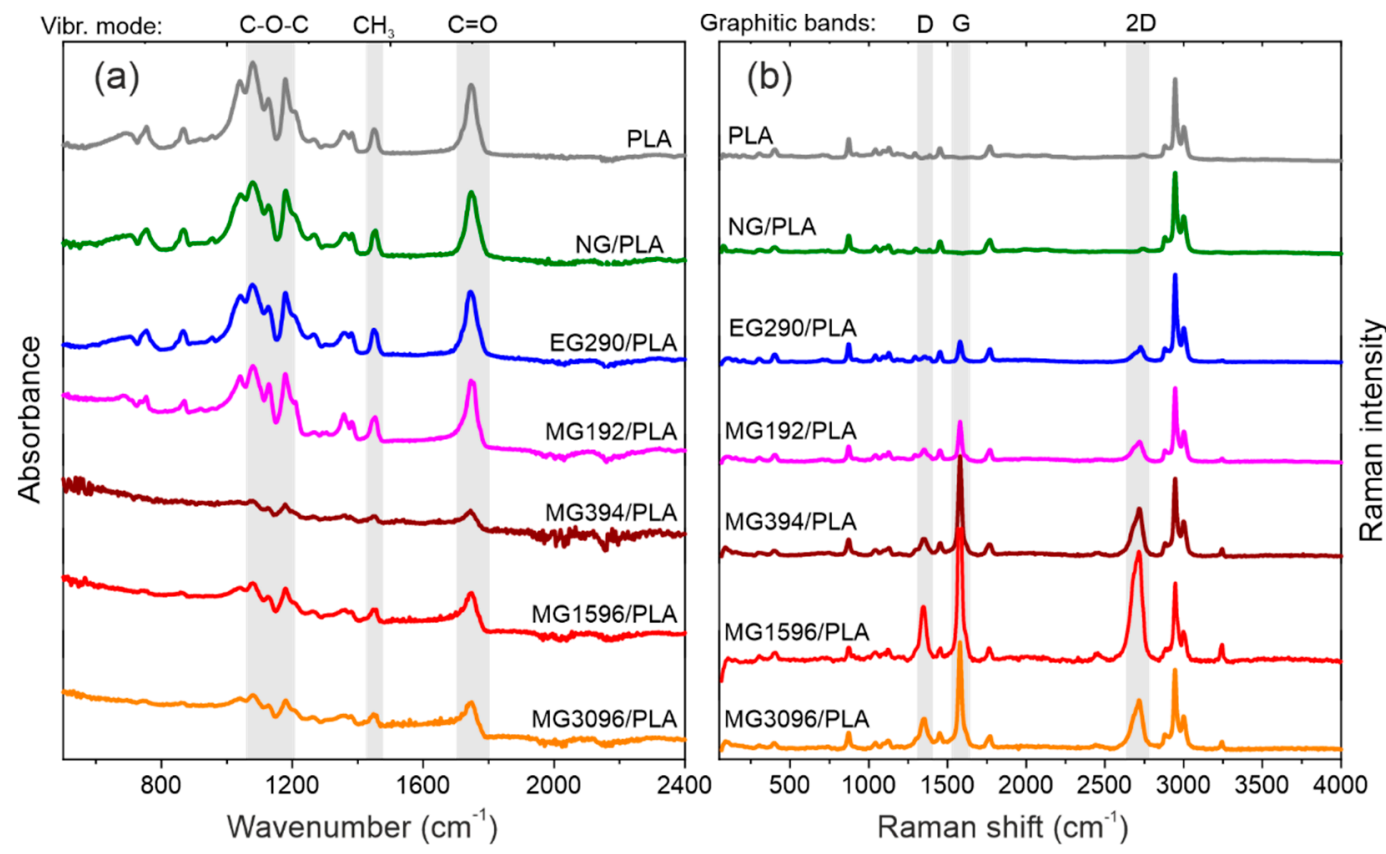

Figure 2. ATR-FTIR (a) and Raman scattering (b) spectra of graphite/PLA composites.

The presence of graphite fillers does not affect the position and relative intensities of the characteristic PLA bands. However, due to the presence of the delocalized $\pi$-electrons that affect the optical properties of graphite, there is a strong correlation between the size of the graphite grains and the intensity of the absorption background $[16,17]$. When the size of the graphite grains is comparable with the wavelength of IR radiation $(4-20 \mu \mathrm{m})$, the strong absorption background from the graphite fillers partially obscures the characteristic bands from the PLA matrix (spectra MG394/PLA, MG1596/PLA, MG3096/PLA in Figure 2a).

In Raman spectra shown in Figure $2 b$, a band at $873 \mathrm{~cm}^{-1}$ attributed to the stretching modes of the C-COO group of PLA is seen. The following oscillation modes of PLA visible in FTIR spectra are also Raman-active: the stretching modes of the $\mathrm{C}-\mathrm{CH}_{3}$ group appear at $1043 \mathrm{~cm}^{-1}$, symmetric stretching modes of C-O-C group is found at $1095 \mathrm{~cm}^{-1}$, the rocking modes of the $\mathrm{CH}_{3}$ group appears at $1126 \mathrm{~cm}^{-1}$, the asymmetric bending modes of the $\mathrm{CH}_{3}$ group appears at $1453 \mathrm{~cm}^{-1}$, the stretching modes of the ester group appear at $1769 \mathrm{~cm}^{-1}$. The strongest bands derived from PLA occur at 2881, 2946, and $3002 \mathrm{~cm}^{-1}$ and are attributed to the stretching of the $\mathrm{CH}$ and asymmetric stretching of the $\mathrm{CH}_{3}$ group.

The bands of the graphite filler are clearly visible in the Raman spectra. The disorder induced graphitic D band appears at about $1355 \mathrm{~cm}^{-1}$. Its intensity is relatively low compared to the main graphitic band that appears at $1580 \mathrm{~cm}^{-1}$. That indicates a wellordered graphite structure and low concentration of the defects [18]. At $2730 \mathrm{~cm}^{-1}$, there is a 2D graphite band. It is red-shifted by $10 \mathrm{~cm}^{-1}$ in fillers with smaller grain sizes (MG192, MG394, MG1596 and MG3096). The intensity of the graphite bands in relation to the PLA bands is greater with increasingly smaller grains of the filler. This is indirect evidence of the homogeneity of the composite.

\subsection{Thermal Behavior and Stability Analysis}

The thermal stability of the graphite/PLA composites was examined using TG analyses (Figure 3a). The temperature at which $5 \%$ weight loss occurred, $T_{5}$, was assumed as the onset of the decomposition process. The maximum slopes of the TGA curves corresponding to the temperature at maximum degradation process rate, $T_{\max }$, were determined from the position of the peaks on the DTG curves shown in Figure 3b [19]. The thermal parameters of the composite samples, such as $T_{5}, T_{\max }$, and mass loss at $900{ }^{\circ} \mathrm{C}, \Delta m_{900}$, are summarized in Table 2. 

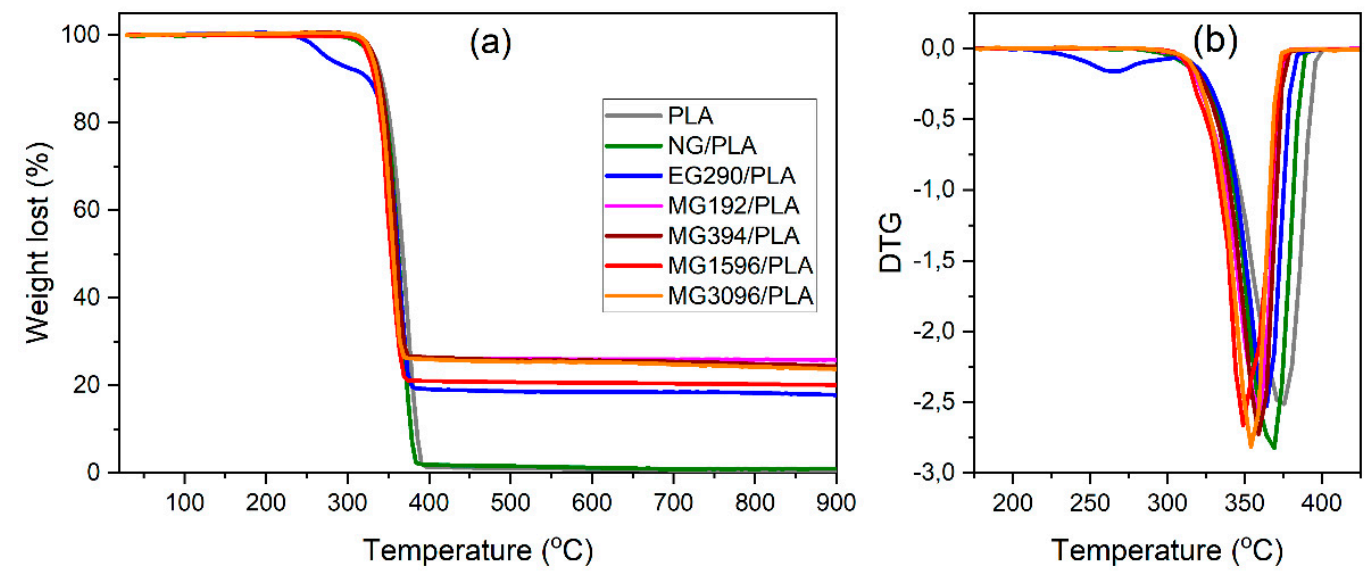

Figure 3. Thermogravimetric curves of graphite/PLA composites: (a) TG plots (b) DTG plots.

Table 2. Thermal parameters obtained from TG and DTG curves of graphite/PLA composites.

\begin{tabular}{lccc}
\hline \multicolumn{1}{c}{ Sample } & $\boldsymbol{T}_{\mathbf{5}}\left({ }^{\circ} \mathbf{C}\right)$ & $\boldsymbol{T}_{\max }\left({ }^{\circ} \mathbf{C}\right)$ & $\Delta \boldsymbol{m}_{\mathbf{9 0 0}}(\mathbf{\%})$ \\
\hline PLA & 333 & 376 & 99.4 \\
NG/PLA & 329 & 369 & 99.0 \\
EG290/PLA * & - & 364 & 82.2 \\
MG192/PLA & 328 & 360 & 74.2 \\
MG394/PLA & 332 & 364 & 75.7 \\
MG1596/PLA & 328 & 352 & 79.9 \\
MG3096/PLA & 327 & 359 & 76.3 \\
\hline
\end{tabular}

* Due to the overlapping weight loss associated with EG290 expansion and PLA thermal degradation, $T_{5}$ is difficult to quantify.

The mass loss, $\Delta m_{900}$, at $900{ }^{\circ} \mathrm{C}$ roughly corresponds to the PLA content in the samples. Residues in the samples PLA and NG/PLA ( $0.6 \%$ and $1.0 \%$, respectively) are related to the presence of impurities and ash formed as a result of thermal degradation of PLA. In the EG290/PLA sample, weight loss is observed when the temperature exceeds $200^{\circ} \mathrm{C}$. This behavior indicates the expansion of expandable graphite EG290 in an inert atmosphere. The TG analyses in air (not presented in this paper) show that, at temperatures between 200 and $300{ }^{\circ} \mathrm{C}$, the EG290 loses approximately $75 \%$ of its mass. The weight loss in an inert gas atmosphere is much smaller $(10 \%)$, however it occurs at the same temperatures. In the case of other composites, the residues at $900{ }^{\circ} \mathrm{C}$ correspond to the content of graphite micropowders in the materials.

The drop in the $T_{5}$ and $T_{\max }$ of the crude PLA after the melt mixing (sample NG/PLA) is apparent, indicating that PLA undergoes thermal degradation upon processing. As shown by Signori et al. [20], during melt mixing, polymer chain scission and recombination occurs, which result in decreasing average number molecular weight and increasing polydispersity index. As a consequence, the thermal stability of the resin decreases. A further drop in the onset decomposition temperature, $T_{5}$, and maximum process rate, $T_{\max }$, is observed in the samples containing graphite fillers. This result is inconsistent with previous observations reported for expandable graphite in [19] and graphite nanoplatelets [21]. It has been suggested that graphite filler has no major influence on the course of PLA decomposition under nitrogen atmosphere and only weak interaction occurs between PLA and its volatile decomposition products [21]. The slight decrease in the decomposition temperature of PLA is associated with the high thermal conductivity of graphite and graphene [22]. The presence of graphite filler facilitates heat transfer in the sample volume [23-25], thereby reducing the thermal decomposition temperature. High thermal conductivity begins to play a significant role at high graphite filler concentrations. This may be another reason for the discrepancy between the obtained results and previously reported observations. The process is the more efficient the more homogeneous the composite structure is. The 
homogeneity of the structure is influenced by the grain size of the filler. In fact, we observe a tendency for the thermal decomposition temperature to drop as the size of graphite grains decreases.

To investigate more deeply the effect of melt mixing in the presence of different graphite fillers on the stability of the PLA matrix, the DSC traces of graphite/PLA composites were compared with pristine materials (Figure 4). Thermal data, such as the glass transition temperature $\left(T_{\mathrm{g}}\right)$, crystallization temperature $\left(T_{\mathrm{c}}\right)$, cold crystallization temperature $\left(T_{\mathrm{cc}}\right)$, melting temperature $\left(T_{\mathrm{m}}\right)$, crystallization enthalpy $\left(\Delta H_{c}\right)$, cold crystallization enthalpy $\left(\Delta H_{c c}\right)$, and melting enthalpy $\left(\Delta H_{m}\right)$, are summarized in the Table 3.
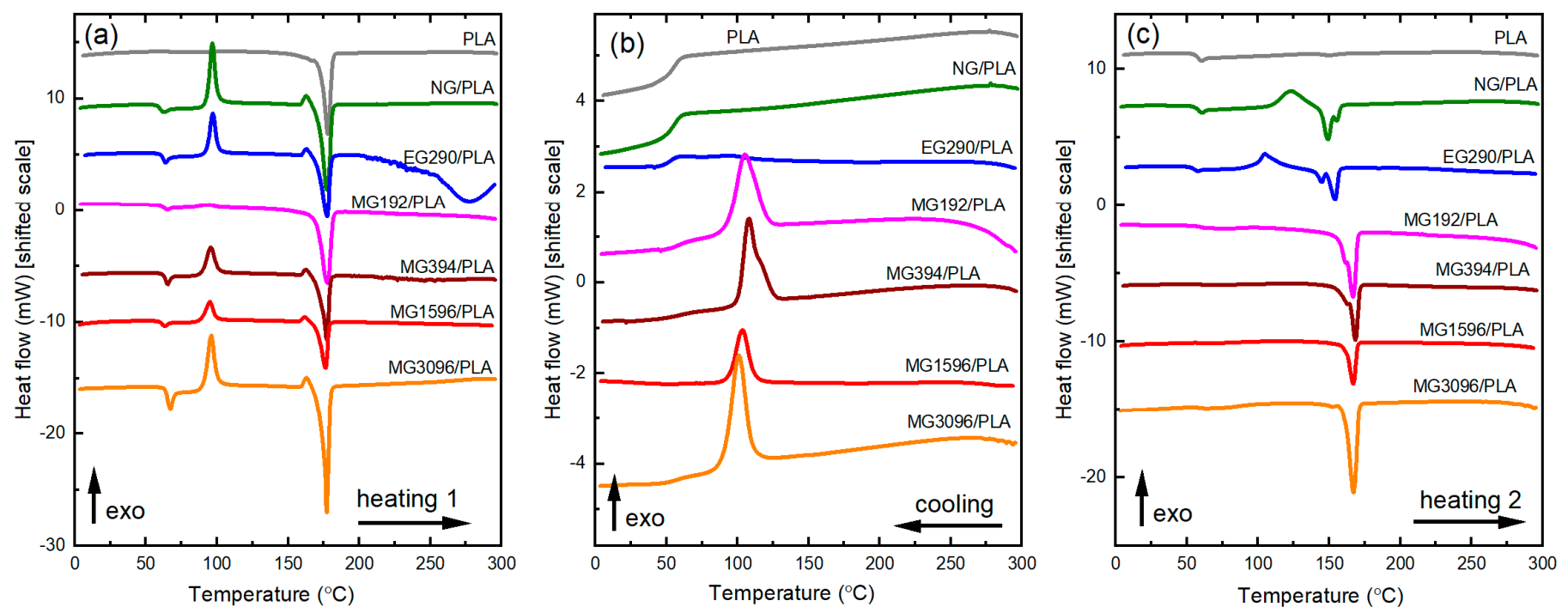

Figure 4. DSC analyses of graphite/PLA composites: (a) first heating, (b) cooling, (c) second heating.

Table 3. Thermal data obtained by DSC for graphite/PLA composites.

\begin{tabular}{|c|c|c|c|c|c|c|c|c|c|c|c|c|}
\hline \multirow[b]{2}{*}{ Sample } & \multicolumn{6}{|c|}{ Heating 1} & \multicolumn{2}{|c|}{ Cooling } & \multicolumn{4}{|c|}{ Heating 2} \\
\hline & $\begin{array}{c}T_{\mathrm{m}} \\
{\left[{ }^{\circ} \mathbf{C}\right]}\end{array}$ & $\begin{array}{l}\Delta H_{m} \\
{[\mathrm{~J} / \mathrm{g}]}\end{array}$ & $\begin{array}{c}T_{\mathrm{g}} \\
{\left[{ }^{\circ} \mathrm{C}\right]}\end{array}$ & $\begin{array}{c}T_{\mathrm{cc}} \\
{\left[{ }^{\circ} \mathrm{C}\right]}\end{array}$ & $\begin{array}{l}\Delta H_{c c} \\
{[\mathrm{~J} / \mathrm{g}]}\end{array}$ & $\begin{array}{l}X_{c}^{1} \\
{[\%]}\end{array}$ & $\begin{array}{c}T_{\mathrm{C}} \\
{\left[{ }^{\circ} \mathbf{C}\right]}\end{array}$ & $\begin{array}{l}\Delta H_{c} \\
{[\mathrm{~J} / \mathrm{g}]}\end{array}$ & $\begin{array}{c}T_{\mathrm{m}} \\
{\left[{ }^{\circ} \mathbf{C}\right]}\end{array}$ & $\begin{array}{l}\Delta H_{m} \\
{[\mathrm{~J} / \mathrm{g}]}\end{array}$ & $\begin{array}{c}T_{\mathrm{g}} \\
{\left[{ }^{\circ} \mathrm{C}\right]}\end{array}$ & $\begin{array}{l}X_{c}^{2} \\
{[\%]}\end{array}$ \\
\hline PLA & 177.78 & 57.22 & - & - & - & 62 & - & - & - & - & 57.56 & 0 \\
\hline NG/PLA & 177.45 & 59.72 & 60.29 & 96.84 & 32.31 & 29 & - & - & $\begin{array}{l}149.20 \\
155.25\end{array}$ & 21.98 & 57.91 & 3 \\
\hline EG290/PLA & 177.58 & 40.54 & 63.97 & 97.13 & 21.74 & 27 & - & - & $\begin{array}{l}155.25 \\
144.64 \\
154.09\end{array}$ & $\begin{array}{c}2.48 \\
11.06\end{array}$ & 57.50 & 6 \\
\hline MG192/PLA & 177.92 & 43.10 & 65.11 & 94.28 & 1.82 & 59 & 105.14 & 23.49 & $\begin{array}{l}162.47 \\
166.86\end{array}$ & 32.06 & - & 46 \\
\hline MG394/PLA & 177.35 & 43.66 & 65.45 & 95.56 & 22.18 & 31 & 107.96 & 28.53 & 163.06 & 35.71 & - & 51 \\
\hline MG1596/PLA & 176.33 & 45.02 & 60.69 & 94.90 & 21.75 & 31 & 103.41 & 22.14 & $\begin{array}{l}100.44 \\
166.88\end{array}$ & 31.68 & - & 43 \\
\hline MG3096/PLA & 176.66 & 36.05 & 65.95 & 96.13 & 22.88 & 30 & 105.30 & 26.86 & $\begin{array}{l}162.40 \\
168.07\end{array}$ & 34.09 & - & 49 \\
\hline
\end{tabular}

The first heating scan of the crude PLA pellets showed an endothermic peak corresponding to the melting of the polymer $\left(T_{\mathrm{m}}=177.8^{\circ} \mathrm{C}\right)$. This peak is not detectable in the second heating scan, proving that the slow crystallization rate of high molecular weight PLA is not conducive to the development of crystalline domains upon cooling [20]. Interestingly, the first heating scan of the processed PLA (NG/PLA) showed an endothermic glass transition at $60.3^{\circ} \mathrm{C}$, followed by an exothermic peak at $96.8^{\circ} \mathrm{C}$ (cold crystallization) and an endothermic peak at $177.5^{\circ} \mathrm{C}$ (melting). The cold crystallization peak is related to the reorganization of amorphous domains into crystalline ones caused by increased macromolecular mobility and flexibility of the processed polymer. Graphite fillers affect the position of the exothermic peak which is slightly shifted to lower temperatures. As revealed by molecular simulations, local mobility of the polymer chains near the graphite 
phase are highly anisotropic and dramatically reduced in the direction perpendicular to the graphite basal planes [26]. Thus, graphite filler can act as a nucleating agent that promotes the crystallization process. As a consequence, the $T_{\mathrm{cc}}$ decreases. The effect of the $T_{\mathrm{cc}}$ lowering does not occur in the composite containing expandable graphite (sample EG290/PLA) due to the large size of graphite flakes $(\sim 00 \mu \mathrm{m})$ which makes it difficult to obtain good dispersion of graphite in the polymer matrix. Graphite fillers affect the cold crystallization enthalpy, $\Delta H_{c c}$, as well. In general, the enthalpy change associated with cold crystallization is lower in the presence of graphite filler. The observed differences can be explained by the quality of the crystallites formed during cold crystallization. The lower crystallization enthalpy results in the formation of less perfect crystallites, capable of recrystallization during DSC analysis. The melting point, $T_{\mathrm{m}}$, of all samples is comparable. The melting enthalpy, $\Delta H_{m}$, of the processed NG/PLA sample is similar to the crude PLA and about $15-20 \mathrm{~J} / \mathrm{g}$ higher than the melting enthalpy of the graphite containing samples. Since the crystallinity estimated from the first heating scan is at a similar level in the melt mixed PLA and melt mixed graphite/PLA composites (except for MG192/PLA sample), it can be assumed that the quality of the formed crystallites is responsible for the change of the melting enthalpy.

It is worth noting that the first DSC scan of the composite EG290/PLA showed a broad endothermic peak above $200{ }^{\circ} \mathrm{C}$ corresponding to the thermal expansion of the expandable graphite EG290.

Cooling scans confirmed the promoting role of the graphite filler in the crystallization process [27]. The exothermic crystallization peaks appeared only in the samples containing graphite filler. The exception is expandable graphite (EG290 filler), which is graphite chemically treated in concentrated sulfuric acid. As the cooling curves of PLA, NG/PLA, and EG290/PLA samples are similar to each other, we conclude that sulfur compounds released during the first heating inhibit the crystallization of the PLA matrix.

During the second heating, bimodal thermal transitions occur, which are manifested by two endothermic peaks. The two melting peaks are related to the presence of two types of crystallites of different sizes and disorder [28]. The melting peak at lower temperature is attributed to the melting and recrystallization of the primary crystals into a more stable form. The second peak appearing at higher temperature corresponds to the melting of the newly formed crystals [29]. The shift of the position of both melting peaks towards higher temperatures is very pronounced in composites with unmodified graphite. This supports the occurrence of less degradation of the polymer matrix during the first heating and the nucleation action of graphite filler. The melting point increase is not observed in the composite containing expanded graphite. Probably, the sulfur compounds released during the first heating accelerate the degradation of the polymer matrix.

The room temperature crystallinity, $X_{c}$, in the neat polymer decreased after each heating cycle. The $X_{c}$ of the pristine PLA estimated from the first heating curve was found to be $62 \%$. In PLA subjected to the melt mixing (sample NG/PLA), the $X_{c}$ decreased to the $29 \%$. The second heating caused the crystallinity to drop to almost zero in both the PLA and NG/PLA samples. The presence of graphite admixture causes a slight decrease in crystallinity observed during the first heating cycle. However, the role of chemically unmodified graphite as a nucleating agent is growing with the history of processing. It is manifested by increased crystallinity estimated from the second heating scan. The highest percent crystalline content (51\%) was found in the composite containing graphite with a grain size of $14 \mu \mathrm{m}$ (sample MG394/PLA). In the remaining samples with unmodified graphite as filler, the crystallinity is slightly lower, but still exceeds $40 \%$. This behavior is evidence of the nucleating action of the graphite filler. On the other hand, the use of the expandable graphite as a filler (EG290) does not produce this effect. Crystallinity determined from the second heating data increased slightly in relation to neat PLA to the level of $6 \%$. Expandable graphite is intercalated with sulfur compounds that are released during thermal treatment and inhibit the crystallization processes. 
It is known that graphite fillers may affect the thermal stability of biodegradable polyesters such as PLA, which usually inhibit thermal oxidation [30].

To investigate how the melt mixing and presence of graphite fillers affect the resistance to oxidation, we have recorded isothermal thermograms at $230^{\circ} \mathrm{C}$ (Figure 5). The changes in heat flow accompanying oxidation are greater in PLA samples than in graphite/PLA composites.

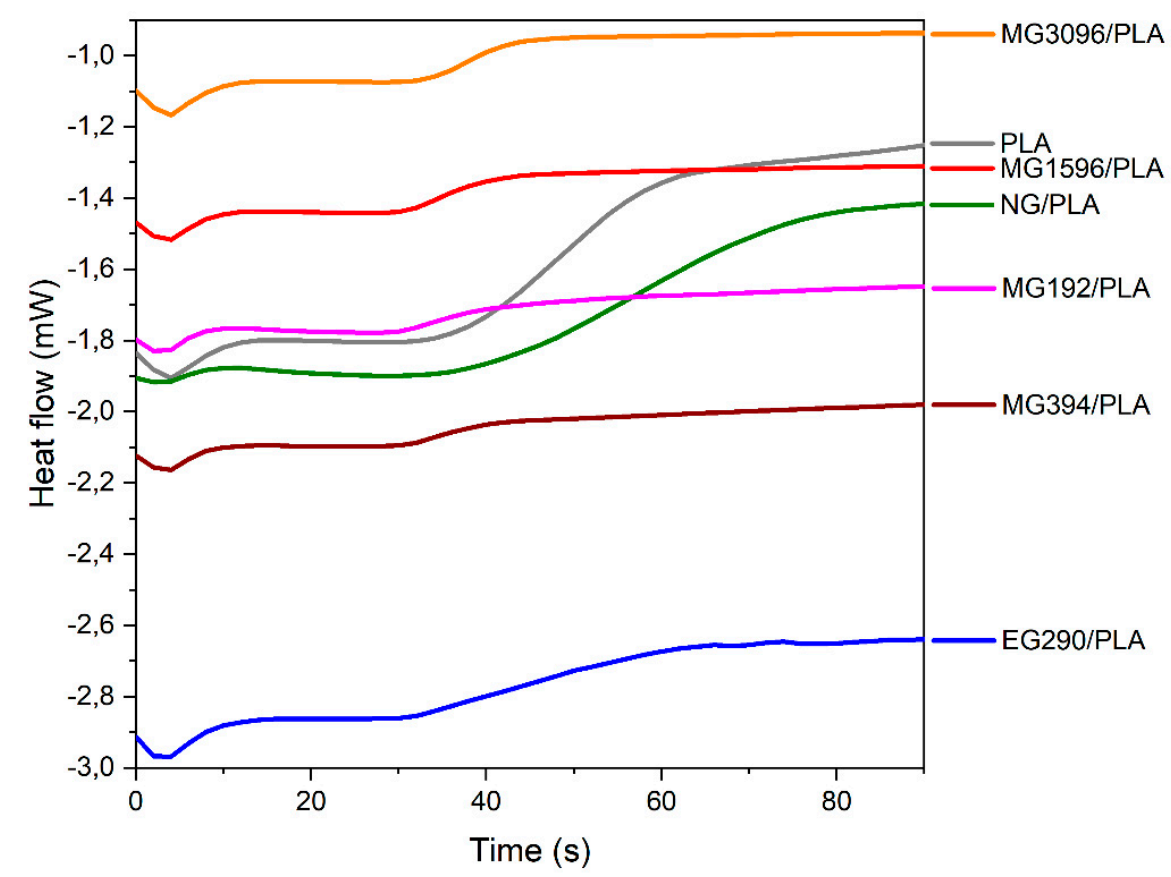

Figure 5. DSC thermograms at $230{ }^{\circ} \mathrm{C}$ for oxidation induction time analyses.

The onset times of the exothermic reaction (OIT) are summarized in Table 4. No differences between PLA and NG/PLA were observed, proving that processing of the neat PLA does not affect the resistivity of PLA to oxidation. The thermal stability of graphite/PLA composites is reduced compared to neat PLA. The reduced value of OIT is mainly caused by the porous morphology of composite samples (higher specific surface) that facilitates oxygen access to the PLA matrix.

Table 4. OIT values with standard deviations.

\begin{tabular}{cc}
\hline Sample & OIT [s] \\
\hline PLA & $38 \pm 2$ \\
NG/PLA & $38 \pm 3$ \\
EG290/PLA & $32 \pm 2$ \\
MG192/PLA & $31 \pm 1$ \\
MG394/PLA & $31 \pm 2$ \\
MG1596/PLA & $31 \pm 1$ \\
MG3096/PLA & $33 \pm 4$ \\
\hline
\end{tabular}

The percent crystalline content of a polymer can be used to tailor the melt flow rate for specific melt processing. Table 5 summarizes the MFR values of the PLA and graphite/PLA composites obtained by melt mixing at $190^{\circ} \mathrm{C}$. The MFR of the PLA subjected to the melt mixing is slightly lower than that of the crude PLA, indicating a correlation between the changes in the polymer structure resulting from the melt processing and the flow resistance [31]. However, confirmation of this observation requires further work involving the measurement of the intrinsic viscosity of polymer solutions. The MFR values of graphite/PLA composites are about half lower than the neat PLA. Many authors 
attribute the decrease in MFR to increased flow resistance associated with the use of solid filler [32,33]. As reported by Wang et al. [34], collisions and friction between the filler particles limit the mobility of the molecular chains. A similar explanation for the decrease in MFR values in the polymer composites with graphite nanoplatelets has been proposed by Duguay et al. [35], who also have linked the flow resistance with the grain size of the nanoplatelets. Indeed, in the MG394/PLA, MG1596/PLA, and MG3096/PLA samples containing, respectively, 14, 10, and $6 \mu \mathrm{m}$ graphite grains, we also observe an increase in the MFR value with decreasing filler grain size.

Table 5. MFR values with standard deviations.

\begin{tabular}{cc}
\hline Sample & MFR (g/10 min) \\
\hline PLA & $69.1 \pm 3.5$ \\
NG/PLA & $64.9 \pm 1.6$ \\
EG290/PLA & $>125$ \\
MG192/PLA & $31.3 \pm 1.2$ \\
MG394/PLA & $23.9 \pm 0.9$ \\
MG1596/PLA & $25.9 \pm 1.7$ \\
MG3096/PLA & $31.4 \pm 1.2$ \\
\hline
\end{tabular}

On the other hand, the MFR values correlate with the percent crystalline content of the PLA matrix derived from the DSC second heating scan shown in Table 3. It is worth noting that the crystallinity estimated from the DSC second heating scan accurately reflects the processing history of materials subjected to MFR tests. Comparing the DSC results with the MFR values, we come to the conclusion that the increased crystallinity of the polymer matrix has a direct impact on the decreased MFR value. The greater the percent of the crystalline content, the lower the melt flow rate. Even with a relatively high content of graphite filler $(\sim 20 \%)$, the crystallinity of the polymer matrix has a greater influence on the flow rate than the friction between the grains of the graphite filler.

The extremely high MFR value of the EG290/PLA composite is related to the low crystallinity of the polymer matrix and delamination processes of expandable graphite at elevated temperatures, which radically reduce the shear friction in the melted composite.

\section{Conclusions}

The introduction of graphite fillers into the PLA matrix resulted in the modification of the thermal and melt flow properties of the composites. FTIR and Raman spectroscopy analyses do not indicate changes in the chemical structure of the polymer matrix and the graphite filler.

TG analyses of the materials under nitrogen show a slight drop of the thermal decomposition temperature of the PLA matrix mixed with graphite. We attribute this behavior to the high thermal conductivity of graphite that facilitates heat transfer in the sample volume, thereby reducing the thermal decomposition temperature. The DSC data track the thermal transitions that occur during the thermal processing. While no effect of graphite filler on the melting temperature was observed during the first heating scan, an apparent increase in the melting temperature is seen during the second heating, proving the slower degradation of the PLA matrix. The influence of the graphite filler on the crystallinity of the polymer matrix is also enhanced with the thermal processing history. The crystallinity determined from the first heating scan is slightly lower in the presence of graphite. The value of this parameter obtained from the second heating increases from $0 \%$ in the neat polymer to about $50 \%$ in graphite/PLA composites. This result is prospective for the design of cheap, biodegradable composite materials for a specific melt processing (melt molding, 3D printing, etc.).

The addition of graphite to PLA causes a slight reduction in the oxidation induction time. Lower resistance to oxygen is related to the porosity of the composite after melt mixing. MFR values are strictly correlated with the crystallinity of the polymer matrix 
estimated from the DSC second heating data. The greater the percent of the crystalline content, the lower the melt flow rate. Hence, we conclude that the presence of the graphite filler has a secondary effect on the melt flow rate of the composites. This statement does not apply to the expandable graphene filler EG290 (which is indeed an intercalated graphite compound). Delamination of graphite layers that occurs at elevated temperature reduces the shear friction that results in the extremely high melt flow rate We show that the correlation between the size of the graphite filler grains and thermal processing parameters of the graphite/PLA composites is rather weak. Taking into account the melting point and crystallinity, the optimal size of the graphite grains in terms of the composite processability is $\sim 14 \mu \mathrm{m}$. Nevertheless, the results presented show the path to designing composite materials based on graphite of industrial grade for specific thermal processing.

Author Contributions: Conceptualization, D.K. and P.S.; methodology, D.K., K.F., A.R.-K., G.D., M.M. and P.S.; formal analysis, D.K., P.S. and P.M.; investigation, D.K., K.F., P.M. and P.S.; writingoriginal draft preparation, D.K. and P.S.; review and editing, D.K., K.B., A.R.-K. and P.S.; visualization, D.K. and P.S.; supervision, G.D. and M.M.; project administration, D.K., G.D. and P.S. All authors have read and agreed to the published version of the manuscript.

Funding: This work is supported by the Ministry of Education and Science of the Republic of Poland as part of the "Implementation doctorate" program (contract no. DWD/4/71/2020) and by the Faculty of Mechatronics of the Kazimierz Wielki University (funds from the subsidy for scientific research).

Institutional Review Board Statement: Not applicable.

Informed Consent Statement: Not applicable.

Data Availability Statement: The data presented in this study are available on request from the corresponding author.

Acknowledgments: The authors thank Marek Doering and Przemyslaw Ziolkowski from Institute of Carbon Technologies Sp. z o. o. for help in selecting industrial graphite samples for this research and Rafał Malinowski for helping to interpret DSC results.

Conflicts of Interest: The authors declare no conflict of interest.

\section{References}

1. Di Lorenzo, M.L.; Androsch, R. Synthesis, Structure and Properties of Poly (lactic acid). In Advances in Polymer Science; Springer: Berlin/Heidelberg, Germany, 2018; Volume 279.

2. Raquez, J.-M.; Habibi, Y.; Murariu, M.; Dubois, P. Polylactide (PLA)-based nanocomposites. Prog. Polym. Sci. 2013, 38, 1504-1542. [CrossRef]

3. Gonçalves, C.; Gonçalves, I.C.; Magalhães, F.; Pinto, A.M. Poly(lactic acid) Composites Containing Carbon-Based Nanomaterials: A Review. Polymers 2017, 9, 269. [CrossRef]

4. Arriagada, P.; Palza, H.; Palma, P.; Flores, M.; Caviedes, P. Poly(lactic acid) composites based on graphene oxide particles with antibacterial behavior enhanced by electrical stimulus and biocompatibility. J. Biomed. Mater. Res. Part A 2017, 106, 1051-1060. [CrossRef]

5. Kim, M.; Jeong, J.H.; Lee, J.Y.; Capasso, A.; Bonaccorso, F.; Kang, S.H.; Lee, Y.K.; Lee, G.H. Electrically conducting and mechanically strong graphene-polylactic acid composites for 3D printing. ACS Appl. Mater. Interfaces 2019, 11, 11841-11848. [CrossRef]

6. Tolvanen, J.; Hannu, J.; Hietala, M.; Kordas, K.; Jantunen, H. Biodegradable multiphase poly(lactic acid)/biochar/graphite composites for electromagnetic interference shielding. Compos. Sci. Technol. 2019, 181, 107704. [CrossRef]

7. Wei, B.; Zhang, L.; Yang, S. Polymer composites with expanded graphite network with superior thermal conductivity and electromagnetic interference shielding performance. Chem. Eng. J. 2020, 404, 126437. [CrossRef]

8. Kopinke, F.-D.; Remmler, M.; Mackenzie, K. Thermal decomposition of biodegradable polyesters-I: Poly ( $\beta$-hydroxybutyric acid). Polym. Degrad. Stab. 1996, 52, 25-38. [CrossRef]

9. Taubner, V.; Shishoo, R. Influence of processing parameters on the degradation of poly(L-lactide) during extrusion. J. Appl. Polym. Sci. 2001, 79, 2128-2135. [CrossRef]

10. Chen, H.-M.; Zhang, W.-B.; Du, X.-C.; Yang, J.-H.; Zhang, N.; Huang, T.; Wang, Y. Crystallization kinetics and melting behaviors of poly(l-lactide)/graphene oxides composites. Thermochim. Acta 2013, 566, 57-70. [CrossRef]

11. Quan, H.; Zhang, S.-J.; Qiao, J.-L.; Zhang, L.-Y. The electrical properties and crystallization of stereocomplex poly(lactic acid) filled with carbon nanotubes. Polymer 2012, 53, 4547-4552. [CrossRef] 
12. Liang, Y.-Y.; Xu, J.-Z.; Liu, X.-Y.; Zhong, G.-J.; Li, Z.-M. Role of surface chemical groups on carbon nanotubes in nucleation for polymer crystallization: Interfacial interaction and steric effect. Polymer 2013, 54, 6479-6488. [CrossRef]

13. Batakliev, T.; Georgiev, V.; Kalupgian, C.; Muñoz, P.A.R.; Ribeiro, H.; Fechine, G.J.M.; Andrade, R.J.E.; Ivanov, E.; Kotsilkova, R. Physico-chemical Characterization of PLA-based Composites Holding Carbon Nanofillers. Appl. Compos. Mater. 2021, 1-18. [CrossRef]

14. Kister, G.; Cassanas, G.; Vert, M. Effects of morphology, conformation and configuration on the IR and Raman spectra of various poly (lactic acid) s. Polymer 1998, 39, 267-273. [CrossRef]

15. Yuniarto, K.; Purwanto, Y.A.; Purwanto, S.; Welt, B.A.; Purwadaria, H.K.; Sunarti, T.C. Infrared and Raman studies on polylactide acid and polyethylene glycol-400 blend. In AIP Conference Proceedings; AIP Publishing LLC: Melville, NY, USA, 2016.

16. Kuzmenko, A.; Van Heumen, E.; Carbone, F.; Van Der Marel, D. Universal Optical Conductance of Graphite. Phys. Rev. Lett. 2008, 100, 117401. [CrossRef]

17. Papoular, R.J.; Papoular, R. Some optical properties of graphite from IR to millimetric wavelengths. Mon. Not. R. Astron. Soc. 2014, 443, 2974-2982. [CrossRef]

18. Cançado, L.G.; Jorio, A.; Ferreira, E.; Stavale, F.; Achete, C.A.; Capaz, R.B.; Moutinho, M.; Lombardo, A.; Kulmala, T.S.; Ferrari, A.C. Quantifying Defects in Graphene via Raman Spectroscopy at Different Excitation Energies. Nano Lett. 2011, 11, 3190-3196. [CrossRef]

19. Fukushima, K.; Murariu, M.; Camino, G.; Dubois, P. Effect of expanded graphite/layered-silicate clay on thermal, mechanical and fire retardant properties of poly (lactic acid). Polym. Degrad. Stab. 2010, 95, 1063-1076. [CrossRef]

20. Signori, F.; Coltelli, M.-B.; Bronco, S. Thermal degradation of poly(lactic acid) (PLA) and poly(butylene adipate-co-terephthalate) (PBAT) and their blends upon melt processing. Polym. Degrad. Stab. 2009, 94, 74-82. [CrossRef]

21. Luyt, A.S.; Kelnar, I. Effect of blend ratio and nanofiller localization on the thermal degradation of graphite nanoplatelets-modified PLA/PCL. J. Therm. Anal. Calorim. 2018, 136, 2373-2382. [CrossRef]

22. Fugallo, G.; Cepellotti, A.; Paulatto, L.; Lazzeri, M.; Marzari, N.; Mauri, F. Thermal Conductivity of Graphene and Graphite: Collective Excitations and Mean Free Paths. Nano Lett. 2014, 14, 6109-6114. [CrossRef]

23. Lebedev, S.; Gefle, O.; Amitov, E.; Berchuk, D.; Zhuravlev, D. Poly(lactic acid)-based polymer composites with high electric and thermal conductivity and their characterization. Polym. Test. 2017, 58, 241-248. [CrossRef]

24. Guo, R.; Ren, Z.; Bi, H.; Xu, M.; Cai, L. Electrical and Thermal Conductivity of Polylactic Acid (PLA)-Based Biocomposites by Incorporation of Nano-Graphite Fabricated with Fused Deposition Modeling. Polymers 2019, 11, 549. [CrossRef] [PubMed]

25. Barkhad, M.; Abu-Jdayil, B.; Mourad, A.; Iqbal, M. Thermal Insulation and Mechanical Properties of Polylactic Acid (PLA) at Different Processing Conditions. Polymers 2020, 12, 2091. [CrossRef]

26. Harmandaris, V.; Daoulas, K.; Mavrantzas, V.G. Molecular Dynamics Simulation of a Polymer Melt/Solid Interface: Local Dynamics and Chain Mobility in a Thin Film of Polyethylene Melt Adsorbed on Graphite. Macromolecules 2005, 38, 5796-5809. [CrossRef]

27. Sullivan, E.M.; Oh, Y.J.; Gerhardt, R.; Wang, B.; Kalaitzidou, K. Understanding the effect of polymer crystallinity on the electrical conductivity of exfoliated graphite nanoplatelet/polylactic acid composite films. J. Polym. Res. 2014, 21, 1-9. [CrossRef]

28. Ahmed, J.; Mulla, M.Z.; Vahora, A.; Bher, A.; Auras, R. Polylactide/graphene nanoplatelets composite films: Impact of highpressure on topography, barrier, thermal, and mechanical properties. Polym. Compos. 2021, 42, 2898-2909. [CrossRef]

29. Bartczak, Z.; Galeski, A.; Kowalczuk, M.; Sobota, M.; Malinowski, R. Tough blends of poly (lactide) and amorphous poly ([R, S]-3-hydroxy butyrate)-morphology and properties. Eur. Polym. J. 2013, 49, 3630-3641. [CrossRef]

30. Margolin, A.; Monakhova, T.; Nedorezova, P.; Klyamkina, A.; Polschikov, S. Effects of graphene on thermal oxidation of isotactic polypropylene. Polym. Degrad. Stab. 2018, 156, 59-65. [CrossRef]

31. Mysiukiewicz, O.; Barczewski, M.; Skórczewska, K.; Matykiewicz, D. Correlation between Processing Parameters and Degradation of Different Polylactide Grades during Twin-Screw Extrusion. Polymers 2020, 12, 1333. [CrossRef] [PubMed]

32. Przekop, R.E.; Kujawa, M.; Pawlak, W.; Dobrosielska, M.; Sztorch, B.; Wieleba, W. Graphite Modified Polylactide (PLA) for 3D Printed (FDM/FFF) Sliding Elements. Polymers 2020, 12, 1250. [CrossRef] [PubMed]

33. Bieliński, M.; Kotewicz, P. Technologiczne aspekty recyklingu tworzyw porowatych. Inżynieria Apar. Chem. 2010, 5, $20-21$.

34. Wang, L.; Hong, J.; Chen, G. Comparison study of graphite nanosheets and carbon black as fillers for high density polyethylene. Polym. Eng. Sci. 2010, 50, 2176-2181. [CrossRef]

35. Duguay, A.J.; Kiziltas, A.; Nader, J.W.; Gardner, D.J.; Dagher, H.J. Impact properties and rheological behavior of exfoliated graphite nanoplatelet-filled impact modified polypropylene nanocomposites. J. Nanopart. Res. 2014, 16, 1-11. [CrossRef] 